\title{
Stereoisomeric Prodrugs to Improve Corneal Absorption of Prednisolone: Synthesis and In Vitro Evaluation
}

\author{
Ye Sheng, ${ }^{1}$ Xiaoyan Yang, ${ }^{1}$ Zhiying Wang, ${ }^{1}$ and Ashim K. Mitra ${ }^{1,2}$
}

Received 26 June 2015; accepted 19 August 2015; published online 3 September 2015

\begin{abstract}
A series of stereoisomeric prodrugs have been designed to examine efficacy in generating higher corneal absorption relative to prednisolone. Prodrugs have been studied and identified with LC/MS/MS and NMR analyses. Prodrugs have been characterized for aqueous solubility, buffer stability, and cytotoxicity. Cellular uptake and permeability studies have been conducted across MDCK-MDR1 cells to determine prodrug affinity towards P-glycoprotein (P-gp) and peptide transporters. Enzyme-mediated degradation of prodrugs has been determined using Statens Seruminstitut rabbit cornea (SIRC) cell homogenates. Prodrugs exhibited higher aqueous solubility relative to prednisolone. Prodrugs circumvented P-gp-mediated cellular efflux and were recognized by peptide transporters. Prodrugs (DP, DDP) produced with D-isomers (D-valine) were significantly stable against both chemical and enzymatic hydrolyses. The order of degradation rate constants observed in chemical and enzymatic hydrolyses were in the same order, i.e., L-valine-L-valine-prednisolone (LLP) $>$ L-valine-D-valine-prednisolone (LDP) $>$ Dvaline-L-valine-prednisolone (DLP) $>$ D-valine-D-valine-prednisolone (DDP). Results obtained from this study clearly suggest that stereoisomeric prodrug approach is an effective strategy to overcome P-gpmediated efflux and improve transcorneal permeability of prednisolone following topical administration.
\end{abstract}

KEY WORDS: Homogenate; Prodrugs; Prednisolone; P-gp; Stereoisomeric; SIRC; Transport.

\section{INTRODUCTION}

Prednisolone, a corticosteroid, is generally indicated for the treatment of ocular inflammations, allergic reactions, and anterior uveitis (1-5). Topical drug delivery is the most preferred method of drug administration for the treatment of ocular diseases affecting anterior tissues of the eye. However, this method of drug administration faces numerous challenges including rapid tear turnover rate, drainage to systemic circulation, and non-specific absorption resulting in lower drug absorption in anterior ocular tissues (6). Moreover, the apical surface of the corneal epithelium expresses drug efflux proteins such as P-glycoprotein (P-gp) $(7,8)$ and multidrug resistance-associated proteins (MRPs) (9-12). These efflux transporters actively pump drug molecules from the cornea back to the tear film $(6,13,14)$. This process further limits drug accumulation in anterior ocular tissues. The cumulative effects of these obstacles result in less than $5 \%$ ocular drug bioavailability following topical administration. Importantly, to generate high transcorneal permeability following topical administration, drugs need to possess an optimum balance between hydrophilicity and lipophilicity properties.

\footnotetext{
${ }^{1}$ Division of Pharmaceutical Sciences, School of Pharmacy, University of Missouri-Kansas City, 2464 Charlotte Street, Kansas City, Missouri 64108, USA.

${ }^{2}$ To whom correspondence should be addressed. (e-mail: mitraa@umkc.edu)
}

Prednisolone is a poorly water soluble drug and an excellent substrate of P-gp (6,15-19).

Transporter-targeted prodrug delivery has been extensively employed to improve drug transport across poorly permeable membranes (20). Peptide transporters have been widely targeted due to high substrate affinity, capacity, and broad specificity. These influx transporters have been demonstrated to be highly expressed on the apical surface of the corneal epithelium (21-23). This transporter has previously been targeted with amino acid and dipeptide prodrugs to improve corneal transport of poorly permeable drugs (2329). Amino acids employed to generate amino acid and dipeptide prodrugs are of L-configuration as L-isomers possess high affinity and specificity towards peptide transporters $(30,31)$. However, the major concern with L-isomers containing dipeptide prodrugs is the lack of enzymatic stability. To modulate the rate of enzymatic degradation, L-isomers at a definite position needs to be replaced by D-isomer (32).

Dipeptide prodrugs containing D-isomers of amino acids have demonstrated significant stability towards enzymaticmediated degradation relative to L-isomers. For instance, Dvaline-D-valine-saquinavir (DDS), L-valine-D-valine-saquinavir (LDS), and D-valine-L-valine-saquinavir (DLS) prodrugs demonstrated higher enzymatic stability relative to L-valine-Lvaline-saquinavir (LLS) $(30,33)$. LDS and DLS displayed an approximately fourfold longer half-life compared to LLS in $0.25 \mathrm{mg} / \mathrm{mL}$ Caco-2 cell homogenates. Similarly, stereoisomeric prodrugs of acyclovir (ACV) demonstrated high enzymatic stability relative to L-valine-L-valine-acyclovir (LLACV) (32). 
In fact, L-valine-D-valine-acyclovir (LDACV), D-valine-L-valine acyclovir (DLACV), and D-valine-D-valine-acyclovir (DDACV) displayed significant enzymatic stability in corneal cell and ocular tissue homogenates (24). The main objective of the present study is to investigate enhanced corneal absorption of stereoisomeric prodrug approach by improving aqueous solubility, corneal permeability, and circumvention of Pgp-mediated cellular efflux of prednisolone. Enzymatic stability of stereoisomeric prodrugs has been determined in Statens Seruminstitut rabbit cornea (SIRC) cell homogenates. To examine P-gp-mediated efflux and peptide transporter affinity of prednisolone and prodrugs, uptake and transport studies have been carried out with MDCK-MDR1 cells.

\section{MATERIALS AND METHODS}

\section{Materials}

Prednisolone was purchased from Sigma-Aldrich (St. Louis, MO). Boc-L-valine and Boc-D-valine were procured from Bachem. [3H]-Gly-Sar (specific activity $4 \mathrm{Ci} / \mathrm{mmol}$ ) and [14C]Erythromycin (specific activity $51.3 \mathrm{mCi} / \mathrm{mmol}$ ) were obtained from Moravek Biochemicals (Brea, CA) and used at a concentration of 1 and $0.5 \mu \mathrm{Ci} / \mathrm{mL}$, respectively. MDCK cells, retrovirally transfected with the human MDR1 cDNA (MDCKII-MDR1), were generously donated by Drs. A. Schinkel and P. Borst (Netherlands Cancer Institute, Amsterdam, Netherlands). SIRC cell line was purchased from American Type Culture Collection (CCL-60; ATCC, Rockville, MD). The growth medium Dulbecco's modified Eagle's medium (DMEM), TrypLE Express and non-essential amino acids, and minimum essential medium (MEM) were procured from Life Technologies (Grand Island, NY). Fetal bovine serum (FBS) was obtained from Atlanta biological. Penicillin, Triton X-100, HEPES, D-glucose, streptomycin, sodium bicarbonate, Boc-valine, dichloromethane, 4-(N,N-dimethylamino) pyridine (DMAP), 1-ethyl-3-(3-dimethylaminopropyl)carbodiimide (EDC), triethyl amine (TEA), trifluoroacetic acid (TFA), sodium chloride $(\mathrm{NaCl})$, potassium chloride $(\mathrm{KCl})$, sodium phosphate $\left(\mathrm{Na}_{2} \mathrm{HPO}_{4}\right)$, potassium phosphate $\left(\mathrm{KH}_{2} \mathrm{PO}_{4}\right)$, calcium chloride $\left(\mathrm{CaCl}_{2}\right)$, magnesium sulfate $\left(\mathrm{MgSO}_{4}\right)$, glucose, and other chemicals were purchased from Sigma Chemical Co. (St. Louis, MO). Culture flasks (75 and $25 \mathrm{~cm}^{2}$ ), 12-well plates $\left(3.8 \mathrm{~cm}^{2}\right.$ growth area/well), and Transwell ${ }^{\circledR}$ were obtained from Costar (Bedford, MA, USA). All chemical agents were of special reagent grade and utilized without any further purification.

\section{Synthesis and Identification of Prodrugs}

Synthesis

L-Valine-L-valine-prednisolone (LLP), L-valine-D-valineprednisolone (LDP), D-valine-L-valine-prednisolone (DLP), and D-valine-D-valine-prednisolone (DDP) prodrugs were synthesized according to a procedure previously described (20). Structures of prodrugs are depicted in Fig. 1. Reagents and reaction conditions were similar for all prodrugs. To synthesize stereoisomeric prodrugs, D-valine has been substituted at a specific position in dipeptide conjugates. D-valine-prednisolone (DP) was synthesized by a method similar to L-valine-prednisolone (LP). To synthesize LDP and DDP, either L- valine or D-valine was conjugated to DP, respectively. For DLP prodrug, D-valine was conjugated to LP.

\section{Identification}

Prodrugs were identified by LC/MS and NMR. LC/MS $(\mathrm{m} / \mathrm{z})$ for LP and DP was +460.4. LC/MS (m/z) for LLP, LDP, DLP, and DDP was +559.5 , respectively.

${ }^{1} \mathrm{H}$ NMR analysis for LP $\left(400 \mathrm{MHz}, \mathrm{DMSO}-\mathrm{d}_{6}\right) \delta 0.80(\mathrm{~s}$, $3 \mathrm{H}), 0.90-0.95(\mathrm{~m}, 1 \mathrm{H}), 0.91-1.02(\mathrm{~m}, 9 \mathrm{H}), 1.18-1.65(\mathrm{~m}$, $14 \mathrm{H}), 1.68-2.40(\mathrm{~m}, 4 \mathrm{H}), 4.18(\mathrm{~s}, 1 \mathrm{H}), 5.23(\mathrm{~s}, 2 \mathrm{H}), 5.90(\mathrm{~s}$, $1 \mathrm{H}), 6.17(\mathrm{~d}, 1 \mathrm{H}), 7.25(\mathrm{~d}, 1 \mathrm{H})$, and $8.05(\mathrm{~s}, 2 \mathrm{H}) .{ }^{13} \mathrm{C} \mathrm{NMR}$ analysis for VP (100 MHz, DMSO-d $\left.)_{6}\right)$ 16.7, 17.5, 19.0, 20.1, 23.8, 27.6, 31.2, 31.8, 32.0, 32.5, 32.8, 33.2, 42.1, 47.2, 48.3, 49.8, $56.4,67.5,90.5,121.5,127.6,152.4,167.2,169.0,184.1$, and 203.7.

${ }^{1} \mathrm{H}$ NMR analysis for DP $\left(400 \mathrm{MHz}, \mathrm{DMSO}-\mathrm{d}_{6}\right) \delta 0.80(\mathrm{~s}$, $3 \mathrm{H}), 0.90-0.95(\mathrm{~m}, 1 \mathrm{H}), 0.91-1.02(\mathrm{~m}, 9 \mathrm{H}), 1.18-1.65(\mathrm{~m}$, $14 \mathrm{H}), 1.68-2.40(\mathrm{~m}, 4 \mathrm{H}), 4.21(\mathrm{~s}, 1 \mathrm{H}), 5.23(\mathrm{~s}, 2 \mathrm{H}), 5.90(\mathrm{~s}$, $1 \mathrm{H}), 6.17(\mathrm{~d}, 1 \mathrm{H}), 7.25(\mathrm{~d}, 1 \mathrm{H})$, and $8.05(\mathrm{~s}, 2 \mathrm{H}) .{ }^{13} \mathrm{C} \mathrm{NMR}$ analysis for DP (100 MHz, DMSO-d $\left.{ }_{6}\right)$ 16.7, 17.5, 19.0, 20.1, 23.8, 27.6, 31.2, 31.8, 32.0, 32.5, 32.8, 33.2, 42.1, 47.2, 48.3, 49.8, $57.0,67.5,90.5,121.5,127.6,152.4,167.2,169.0,184.1$, and 203.7 .

${ }^{1} \mathrm{H}$ NMR for LLP $\left(400 \mathrm{MHz}, \mathrm{DMSO}-\mathrm{d}_{6}\right) \delta 0.80(\mathrm{~s}, 3 \mathrm{H})$, 0.90-0.95 (m, 1H), 0.91-1.02 (m, 15H), 1.18-1.65 (m, 14H), $1.68-2.40(\mathrm{~m}, 5 \mathrm{H}), 3.60(\mathrm{~m}, 1 \mathrm{H}), 3.80(\mathrm{~s}, 1 \mathrm{H}), 5.11(\mathrm{~d}, 2 \mathrm{H}), 5.23$ $(\mathrm{s}, 2 \mathrm{H}), 5.90(\mathrm{~s}, 1 \mathrm{H}), 6.17(\mathrm{~d}, 1 \mathrm{H}), 7.25(\mathrm{~d}, 1 \mathrm{H})$, and $8.05(\mathrm{~s}, 1)$. ${ }^{13} \mathrm{C}$ NMR for VVP $\left(100 \mathrm{MHz}, \mathrm{DMSO}-\mathrm{d}_{6}\right)$ 16.7, 17.5, 18.5, 19.0, 20.1, 23.8, 27.6, 30.5, 31.2, 31.8, 32.0, 32.5, 32.8, 33.2, 42.1, 47.2, $48.3,49.8,57.0,59.9,67.5,90.5,121.5,127.6,152.4,167.2$, 169.0, 172.5, 184.1, and 203.7.

${ }^{1} \mathrm{H}$ NMR analysis for DLP and LDP (400 MHz, DMSO$\left.\mathrm{d}_{6}\right) \delta 0.80(\mathrm{~s}, 3 \mathrm{H}), 0.90-0.95(\mathrm{~m}, 1 \mathrm{H}), 0.91-1.02(\mathrm{~m}, 15 \mathrm{H}), 1.18-$ $1.65(\mathrm{~m}, 14 \mathrm{H}), 1.68-2.40(\mathrm{~m}, 5 \mathrm{H}), 3.60(\mathrm{~m}, 1 \mathrm{H}), 4.18(\mathrm{~s}, 1 \mathrm{H})$, $5.11(\mathrm{~d}, 2 \mathrm{H}), 5.23(\mathrm{~s}, 2 \mathrm{H}), 5.90(\mathrm{~s}, 1 \mathrm{H}), 6.17(\mathrm{~d}, 1 \mathrm{H}), 7.25(\mathrm{~d}$, $1 \mathrm{H})$, and 8.05 (s, 1). ${ }^{13} \mathrm{C}$ NMR analysis for DLP $(100 \mathrm{MHz}$, DMSO-d $\left.{ }_{6}\right)$ 16.7, 17.5, 18.5, 19.0, 20.1, 23.8, 27.6, 30.5, 31.2, 31.8, 32.0, 32.5, 32.8, 33.2, 42.1, 47.2, 48.3, 49.8, 56.4, 59.9, 67.5, $90.5,121.5,127.6,152.4,167.2,169.0,172.5,184.1$, and 203.7.

${ }^{1} \mathrm{H}$ NMR analysis for DDP (400 MHz, DMSO-d $\left.{ }_{6}\right) \delta 0.80$ $(\mathrm{s}, 3 \mathrm{H}), 0.90-0.95(\mathrm{~m}, 1 \mathrm{H}), 0.91-1.02(\mathrm{~m}, 15 \mathrm{H}), 1.18-1.65(\mathrm{~m}$, $14 \mathrm{H}), 1.68-2.40(\mathrm{~m}, 5 \mathrm{H}), 3.60(\mathrm{~m}, 1 \mathrm{H}), 4.21(\mathrm{~s}, 1 \mathrm{H}), 5.11(\mathrm{~d}$, $2 \mathrm{H}), 5.23(\mathrm{~s}, 2 \mathrm{H}), 5.90(\mathrm{~s}, 1 \mathrm{H}), 6.17(\mathrm{~d}, 1 \mathrm{H}), 7.25(\mathrm{~d}, 1 \mathrm{H}), 8.05$ (s, 1). ${ }^{13} \mathrm{C}$ NMR analysis for DDP (100 MHz, DMSO-d $\left.\mathrm{d}_{6}\right) 16.7$, 17.5, 18.5, 19.0, 20.1, 23.8, 27.6, 30.5, 31.2 , 31.8, 32.0, 32.5, 32.8, 33.2 , 42.1, 47.2, 48.3, 49.8, 57.0, 59.9, 67.5, 90.5, 121.5, 127.6, 152.4, 167.2, 169.0, 172.5, 184.1, and 203.7.

Purity of all prodrugs was observed to be more than $95 \%$, as determined by HPLC analysis.

\section{Methods}

\section{Cell Culture}

MDCK-wild type (MDCK-WT) and MDCK-MDR1 cells (passages 6-10) were cultivated in DMEM supplemented with $10 \%$ FBS (heat inactivated), penicillin (100 units $/ \mathrm{mL}$ ) and streptomycin $(100 \mu \mathrm{g} / \mathrm{mL}), \mathrm{pH}$ at $7.4 \mathrm{in} 75 \mathrm{~cm}^{2}$ tissue culture flask. SIRC cells were grown in MEM supplemented with $10 \%$ calf serum, lactalbumin $(1.76 \mathrm{mg} / \mathrm{mL})$, HEPES $(1.3 \mathrm{mg} / \mathrm{mL})$, and 


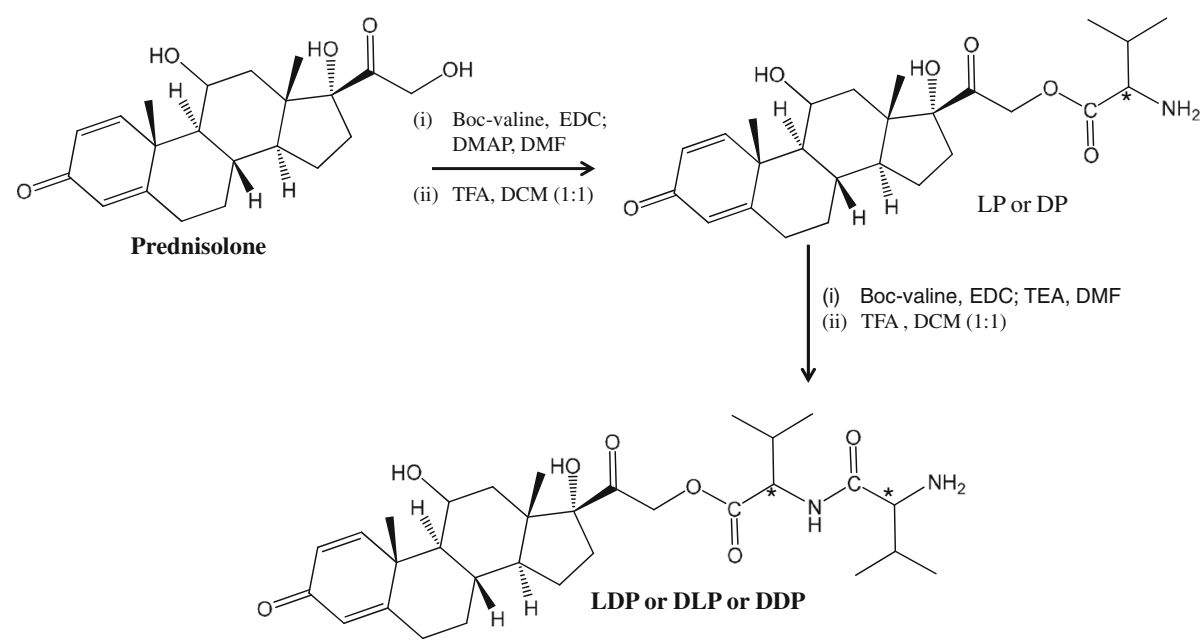

Fig. 1. Synthesis of amino acid and dipeptide prodrugs of prednisolone. Reagents used to synthesize prodrugs are provided. Asterisk (*) sign has been used to show the D- and/or L-valine used for prodrug synthesis

penicillin-streptomycin $(100 \mu \mathrm{g} / \mathrm{mL})$ at $\mathrm{pH}$ 7.4. Cells were maintained at $37^{\circ} \mathrm{C}$ in an atmosphere of $5 \% \mathrm{CO}_{2}$ and $90 \%$ relative humidity. The medium was changed on every alternate day until cells reached $90 \%$ confluency (6-7 days for MDCK-MDR1 cells and 8-10 days for SIRC cells).

\section{Aqueous Solubility Studies}

Aqueous solubility was determined by adding $5 \mathrm{mg}$ of each compound to $0.5 \mathrm{~mL}$ distilled deionized water (DDW) and vortexed vigorously to generate a saturated solution. Eppendorf tubes were placed in shaking water bath $(60 \mathrm{rpm})$ at $25^{\circ} \mathrm{C}$ for $4 \mathrm{~h}$. Tubes were centrifuged at $12,500 \mathrm{rpm}$ for $10 \mathrm{~min}$ to separate undissolved prodrugs. The supernatant was collected and filtered through $0.45 \mu \mathrm{m}$ Nalgene syringe filter membrane. Appropriate dilutions were made to the supernatant and drug/prodrug concentration was determined by a reversed-phase HPLC.

\section{Buffer Stability Studies}

To study chemical hydrolysis, prodrugs $(20 \mu \mathrm{g} / \mathrm{mL})$ were dissolved in approximately $5 \mathrm{~mL}$ of buffer in centrifuge tubes and placed in shaking water bath (PolyScience ${ }^{\circledR}$ ) at $37^{\circ} \mathrm{C}$ and $60 \mathrm{rpm}$. At predetermined time points, samples $(100 \mu \mathrm{L})$ were withdrawn and stored at $-80^{\circ} \mathrm{C}$ until further HPLC analysis. Prodrug concentrations remaining were plotted versus time in order to determine the degradation rate constants.

\section{Cytotoxicity}

Cytotoxicity of drug/prodrug was determined in MDCKWT cells using lactate dehydrogenase (LDH) assay (Takara Bio Co. St Louis, MO). Briefly, cells were seeded in 96-well culture plates at a density of 20,000 cells per well and incubated at $37^{\circ} \mathrm{C}$ in an atmosphere of $5 \% \mathrm{CO}_{2}$ and $90 \%$ relative humidity. Following incubation, medium was removed and $200 \mu \mathrm{L}$ assay medium (serum free DMEM) containing five different drug/prodrug concentrations $(5-250 \mu \mathrm{M})$ was added into each well. Cells were incubated with drug/prodrug solution for $4 \mathrm{~h}$. Assay medium and 1\% Triton X-100 served as negative and positive control, respectively. LDH release from cells was determined by measuring absorbance with a microplate reader (Bio-Rad, Hercules, CA) at a wavelength of $450 \mathrm{~nm}$.

\section{Cellular Uptake}

Cellular uptake studies were performed according to a protocol published from our laboratory with a minor modification (34). Briefly, cells were plated at a density of $3 \times 10^{6}$ cells in 12 -well culture plates and maintained at $37^{\circ} \mathrm{C}$ in an atmosphere of $5 \% \mathrm{CO}_{2}$ and $90 \%$ relative humidity. On reaching confluency, medium was removed and cell monolayer was washed with $2 \mathrm{~mL}$ of Dulbecco's phosphate buffered saline (DPBS, pH 7.4) for three times at $37^{\circ} \mathrm{C}$ (each wash of $10 \mathrm{~min}$ ). Uptake studies were initiated by incubating cells with radioactive solution in DPBS at $37^{\circ} \mathrm{C}$ for $20 \mathrm{~min}$. Following incubation, radioactive solution was quickly removed and plates were washed three times, $5 \mathrm{~min}$ each, with ice-cold stop solution $(210 \mathrm{mM} \mathrm{KCl}, 2 \mathrm{mM}$ HEPES, $\mathrm{pH}$ of 7.4) to prevent any further uptake. One milliliter of lysis buffer $(0.1 \%$ Triton $\mathrm{X}$ solution in $0.3 \% \mathrm{NaOH}$ ) was added to each well and plates were stored overnight at room temperature for cell lysis. On the following day, $500-\mu \mathrm{L}$ solutions were withdrawn and mixed with $3 \mathrm{~mL}$ of scintillation cocktail in scintillation vials. The radioactivity associated with cells was analyzed using a scintillation counter (Beckman Instruments Inc., Model LS6500 ; Fullerton, CA). Uptake rate was normalized to protein content that was quantified using Bio-Rad protein estimation kit (Bio-Rad protein; Hercules, CA).

For non-radioactive uptake studies, cells were incubated with drug/prodrug $(100 \mu \mathrm{M})$ for $20 \mathrm{~min}$. Following incubation, drug/prodrug solution was removed and cell monolayers were washed three times (each wash of $5 \mathrm{~min}$ ) with ice-cold stop solution. Approximately, $500 \mu \mathrm{L}$ of DMEM was added to each well and plates were stored at $-80^{\circ} \mathrm{C}$ for cell lysis. On the following day, drug/prodrug from each well was extracted with 
liquid-liquid extraction and analyzed with LC/MS/MS technique ("Analysis with LC/MS/MS" section).

\section{Transport Studies}

Transepithelial transport studies were conducted across MDCK-MDR1 cells according to a method previously published from our laboratory with minor modifications (35). Briefly, MDCK-MDR1 cells were seeded in 12-well Transwell ${ }^{\circledR}$ plates. Monolayer integrity was determined by measuring transepithelial electric resistance (TEER), with an EVOM (epithelial volt ohmmeter from World Precision Instruments, Sarasota, FL); TEER value was found to be approximately $220 \Omega \mathrm{cm}^{2}$. Before initiation of a transport study, cell monolayers were washed thoroughly with DPBS ( $\mathrm{pH}$ 7.4) at $37^{\circ} \mathrm{C}$, three times (each wash of $10 \mathrm{~min}$ ). For determining apical to basolateral (A-B) permeability, $0.5 \mathrm{~mL}$ drug/prodrug solution $(100 \mu \mathrm{M})$ was added in the apical chamber of 12 -well Transwell ${ }^{\circledR}$ plates. About $1.5 \mathrm{~mL}$ drug/prodrug solution $(100 \mu \mathrm{M})$ was added in the basolateral chamber to determine B-A transport. Transport study was performed for a period of $3 \mathrm{~h}$ at $37^{\circ} \mathrm{C}$. About $200 \mu \mathrm{L}$ of samples were collected at predetermined time points from the receiving chamber and replaced with fresh DPBS to maintain sink conditions. Samples were stored at $-80^{\circ} \mathrm{C}$ until further analysis by LC/MS/MS technique.

\section{SIRC Cell Homogenate Study}

SIRC cell homogenate study was carried out according to a method previously published from our laboratory with little modifications (35). Briefly, SIRC cells were washed three times with DPBS (pH 7.4) at $37^{\circ} \mathrm{C}(10 \mathrm{~min}$ each wash). Cells were collected with a mechanical scrapper in two volumes of DPBS and homogenized by a Multipro variable speed homogenizer (DREMEL, Racine, WI) in Eppendorf tubes. Tubes were centrifuged at $12,500 \mathrm{rpm}$ for $10 \mathrm{~min}$, and the supernatant was collected and diluted with DPBS ( $\mathrm{pH}$ 7.4) to obtain a final protein concentration of $0.5 \mathrm{mg} / \mathrm{mL}$. To $5 \mathrm{~mL}$ of this supernatant solution, about $15 \mu \mathrm{g} / \mathrm{mL}$ of prodrug was dissolved and placed in shaking water bath $(60 \mathrm{rpm})$ at $37^{\circ} \mathrm{C}$. Samples $(100 \mu \mathrm{L})$ were withdrawn at predetermined time points and equal volume of a mixture of methanol:acetonitrile (1:3) was added to each sample to terminate the enzymatic hydrolysis. Samples were stored at $-80^{\circ} \mathrm{C}$ until further analysis with HPLC technique.

\section{DATA ANALYSIS}

\section{HPLC Analysis}

Solubility, buffer, and cell homogenate stability samples were analyzed with reversed-phase HPLC technique. The HPLC system consisted of Waters 515 HPLC pump, Alcott 718 AL HPLC antosampler, and Pynamax ${ }^{\circledR}$ UV Absorbance detector. A C(8) Luna Column $(250 \mathrm{~mm} \times 4.6 \mathrm{~mm}$; Phenomenex, Torrance, CA) was pumped with a mixture of $60 \%$ of methanol and $40 \%$ of $16 \mathrm{mM}$ potassium dihydrogen phosphate buffer ( $\mathrm{pH} 4.0)$ containing $0.1 \%$ trifluoro acetic acid (TFA) at the flow rate of $0.8 \mathrm{~mL} / \mathrm{min}$. Absorbance wavelength was set at $254 \mathrm{~nm}$. Prednisolone, LP, and LLP were eluted at 7.9, 9.8, and 14.1 min, respectively. DP, DLP, LDP, and DDP were eluted at 10.2, 15.2, 15.8, and $12.7 \mathrm{~min}$, respectively.

\section{Analysis with LC/MS/MS}

\section{Sample Preparation}

To determine drug/prodrug concentrations in cellular accumulation and transport studies, a liquid-liquid extraction technique was employed. Briefly, $50 \mu \mathrm{L}$ of hydrocortisone (IS, $500 \mathrm{ng} / \mathrm{mL}$ ) was added to each sample and extracted with $600 \mu \mathrm{L}$ of ice-cold tert-butyl methyl ether (TBME). Samples were vortexed for $2 \mathrm{~min}$ and centrifuged at 10,000 rpm for $7 \mathrm{~min}$ to separate aqueous phase from the organic phase. Tubes were placed in $-80^{\circ} \mathrm{C}$ for $30 \mathrm{~min}$ and TBME was separated and evaporated under reduced pressure for $45 \mathrm{~min}$. The residue obtained was reconstituted in $100 \mu \mathrm{L}$ mobile phase. Subsequently, $20 \mu \mathrm{L}$ of reconstituted solution was injected into a LC/MS/MS.

\section{LC/MS/MS Analysis}

Cellular uptake and transport samples were analyzed with LC/MS/MS. QTrap ${ }^{\circledR}$ LC/MS/MS mass spectrometer (Applied Biosystems, Foster City, CA, USA) equipped with Agilent 1100 series quaternary pump (Agilent G1311A), vacuum degasser (Agilent G1379A), and autosampler (Agilent G1367A). A C18 XTerra ${ }^{\circledR}$ column $(2.1 \mathrm{~mm} \times 50 \mathrm{~mm})$ was pumped with mobile phase $(80 \%$ acetonitrile and $20 \%$ water containing $0.1 \%$ TFA) at a flow rate of $0.25 \mathrm{~mL} / \mathrm{min}$ and chromatographs were obtained for $4 \mathrm{~min}$. Drug/prodrug and IS were eluted between 2.5-3 min.

Electrospray ionization in the positive mode was applied for the sample introduction. Analytes were detected with a multiple-reaction monitoring (MRM) method. Precursor ions were subjected to collision-induced dissociation to generate daughter ions. Precursor and product ions obtained for LLP, LDP, DLP, and DDP were +559.5/171.2. Precursor and product ions obtained for LP and DP were $+460.4 / 442.1$, prednisolone $+360.9 / 342.9$, and IS $+363.3 / 121.2$. The turbo ion spray setting and collision gas pressure were also optimized (IS voltage $5500 \mathrm{~V}$, temperature $300^{\circ} \mathrm{C}$, nebulizer gas $40 \mathrm{psi}$, curtain gas $40 \mathrm{psi}$ ). MS/MS was performed using nitrogen as the collision gas. Other ion source parameters include declustering potential $(56 \mathrm{~V})$, collision energy $(22 \mathrm{~V})$, entrance potential $(5.5 \mathrm{~V})$, and collision cell exit potential $(4 \mathrm{~V})$. Analytical data for drug/prodrug showed significant linearity in the nanomolar range.

\section{Data Analysis}

\section{Permeability Analysis}

Cumulative amount of transported drug was plotted against time to determine the permeability rate. Linear regression of the amounts transported as a function of time yielded the rate of the transport $(\mathrm{dM} / \mathrm{dt})$, which was divided by the cross-section area $(A)$ of diffusion to obtain steadystate flux $[\mathrm{flux}=(\mathrm{dM} / \mathrm{dt}) / A]$. Steady-state flux was normalized 
with donor concentration $\left(C_{\mathrm{d}}\right)$ to obtain permeability coefficients $\left(\right.$ permeability=flux $/ C_{\mathrm{d}}$ ).

\section{Statistical Analysis}

All experiments were performed at least in quadruplicate and results are expressed as mean \pm standard deviation (S.D.). Statistical comparison of mean values was performed with student $t$ test. A value of $p<0.05$ was considered to be statistically significant.

\section{RESULTS AND DISCUSSION}

\section{Aqueous Solubility Studies}

Aqueous solubility of prednisolone is $0.31 \pm 0.03 \mathrm{mg} / \mathrm{mL}$. Aqueous solubilities of LP and LLP have been previously reported (20). Saturated aqueous solubility generated by DP prodrug was approximately $5.2 \pm 0.2 \mathrm{mg} / \mathrm{mL}$. DP exhibits an approximately 17 -fold higher aqueous solubility relative to prednisolone. LDP, DLP, and DDP displayed saturated aqueous solubilities of $5.2 \pm 0.3,4.6 \pm 0.2$, and $3.4 \pm 0.4 \mathrm{mg} / \mathrm{mL}$, respectively. LDP, DLP, and DDP produced about 17-, 15-, and 11fold higher aqueous solubility relative to prednisolone. Aqueous solubility of all prodrugs was observed to be significantly higher relative to prednisolone. Poor aqueous solubility is one of the major factors that hinders formulation of aqueous ophthalmic solutions of prednisolone. Significant improvement in aqueous solubility by amino acid and dipeptide prodrugs may generate compounds amenable for topical administration. Results obtained from prodrug aqueous solubility are consistent with previously published reports from our laboratory (3638).

\section{Buffer Stability Studies}

Chemical hydrolysis of stereoisomeric prodrugs was determined at various $\mathrm{pH}$ values (3.4, 5.4, and 7.4). Degradation rate constants and half-life values obtained for prodrugs are presented in Table I. Prodrugs were observed to be stable under acidic $\mathrm{pH}$ conditions compared to slightly neutral $\mathrm{pH}$. DP generated lower degradation rate constant at pH 3.4 relative to 7.4. Rate constants of DP at $\mathrm{pH} 3.4,5.4$, and 7.4 were $0.22 \pm 0.04,0.43 \pm 0.08$, and $2.6 \pm 0.5 \times 10^{-3} / \mathrm{min}$, respectively. Degradation rate constant at $\mathrm{pH} 7.4$ was sixfold higher relative to $\mathrm{pH}$ 3.4. Degradation half-lives of DP observed at pH 3.4, 5.4, and 7.4 were $55 \pm 10,28 \pm 5$, and $4.5 \pm 0.9 \mathrm{~h}$, respectively. This result indicated that DP is highly susceptible to alkaline hydrolysis relative to acidic hydrolysis. Similar results have been observed for a wide range of amino acid prodrugs developed previously in our laboratory $(35,36,39,40)$. Lower degradation half-life at $\mathrm{pH} 7.4$ suggests that a large amount of DP may degrade in precorneal tear fluid upon topical administration to regenerate prednisolone.

LDP and DLP stereoisomeric prodrugs exhibited no significant degradation at acidic pHs (3.4 and 5.4). However, these compounds degraded rapidly with the rise in $\mathrm{pH}$ (7.4). The degradation rate constant value displayed by LDP and DLP prodrugs at $\mathrm{pH} 7.4$ was $0.31 \pm 0.02$ and $0.19 \pm 0.07 \times 10^{-3} / \mathrm{min}$, respectively. Degradation half-life produced by LDP and DLP at pH 7.4 was $37 \pm 2$ and $65 \pm 19 \mathrm{~h}$, respectively. DDP prodrug was
Table I. Degradation Rate Constant and Half-Life Values of Prodrugs at Various $\mathrm{pH}$ Conditions

\begin{tabular}{llll}
\hline Prodrugs & $\mathrm{pH}$ & $\begin{array}{l}\text { Degradation rate } \\
\text { constant } \times 10^{-3}\left(\mathrm{~min}^{-1}\right)\end{array}$ & Half-Life (h) \\
\hline DP & 3.4 & $0.22 \pm 0.04$ & $55 \pm 10$ \\
& 5.4 & $0.43 \pm 0.08$ & $28 \pm 5$ \\
& 7.4 & $2.6 \pm 0.5$ & $4.5 \pm 0.9$ \\
LDP & 3.4 & ND & - \\
& 5.4 & ND & - \\
& 7.4 & $0.13 \pm 0.02$ & $37 \pm 2$ \\
DLP & 3.4 & ND & - \\
& 5.4 & ND & - \\
& 7.4 & $0.19 \pm 0.07$ & $65 \pm 19$ \\
DDP & 3.4 & ND & - \\
& 5.4 & ND & - \\
& 7.4 & ND & - \\
\hline
\end{tabular}

Results are expressed as mean \pm standard deviation $(n=4)$. Stability of prednisolone prodrugs under $\mathrm{pH} 3.4,5.4$, and 7.4

$D P$ D-valine-prednisolone, $L D P$ L-valine-D-valine-prednisolone, $D L P$ D-valine-L-valine-prednisolone, $D D P$ D-valine-D-valine-prednisolone, $N D$ not detected

observed to be highly stable with no apparent degradation at all $\mathrm{pH}$ values. Previously, we have examined the susceptibility of LLP prodrug to acidic and alkaline hydrolysis (20). Degradation half-life values generated by LLP at pH 5.4 and 7.4 were $48 \pm 10$ and $27 \pm 5 \mathrm{~h}$, respectively. Interestingly, LDP and DLP prodrugs displayed significantly higher half-life at $\mathrm{pH} 7.4$ relative to LLP. Particularly, DLP prodrug was stable with more than a twofold slower degradation half-life compared to LLP at $\mathrm{pH}$ 7.4. Results obtained from this study clearly suggest that incorporation of Disomers in the dipeptide prodrug structure significantly enhances the stability towards chemical hydrolysis. Moreover, the position of D-isomers in the prodrug structure plays an important role in promoting chemical stability. D-isomer as a terminal moiety (DLP) imparted significant chemical stability to prodrugs relative to L-isomer (LDP). These results were consistent with those observed with stereoisomeric dipeptide prodrugs of saquinavir (33).

\section{Cytotoxicity Studies}

To determine cytotoxicity of stereoisomeric prodrugs in MDCK-WT cells, LDH assay was employed. Medium with no serum and drug/prodrug was selected as negative control (NC). Triton X-100 (1\%) was used as a positive control. Results obtained from this study are depicted in Fig. 2. Triton $\mathrm{X}-100$ displayed an approximately fivefold increase in absorbance relative to control indicating significant cytotoxicity to MDCK-WT cells. Prednisolone did not exhibit any cytotoxic effects in the concentration range 50-250 $\mu \mathrm{M}$. Similarly, DP displayed no significant cytotoxicity in the concentration range of $50-250 \mu \mathrm{M}$ (data not shown). However, dipeptide prodrugs appeared to be slightly toxic at relatively higher concentrations. At $250 \mu \mathrm{M}$ concentration, dipeptide prodrugs generated an approximately twofold higher absorbance relative to NC. Interestingly, prodrugs displayed no cell cytotoxicity in the concentration range of $50-150 \mu \mathrm{M}$ range. Hence, to avoid cytotoxic effects of prodrugs, uptake and transport experiments were carried out at $100 \mu \mathrm{M}$ concentration. 


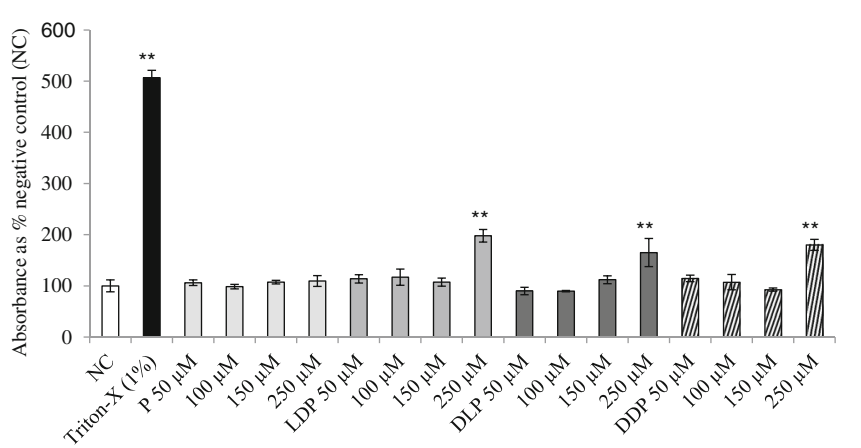

Fig. 2. Cytotoxicity of prednisolone and prodrugs in MDCK-WT cells. Each data point is expressed as mean \pm standard deviation $(n=6)$. Absorbance is represented as percentage of control (no serum and drug in medium). Asterisks $(* *)$ represent significant difference from the control $(p<0.01)$

\section{Cellular Uptake Studies}

Drug efflux pumps such as P-gp are highly expressed on the apical surface of the corneal epithelium $(7,8,41)$. Therefore, $\mathrm{P}$ gp-mediated efflux may play an important role in ocular disposition of therapeutic agents following topical administration. Pgp may be involved in limiting the transcorneal permeability of various therapeutic agents $(6,8,14,27,42)$. Hence, evasion of this efflux pump at corneal epithelium might significantly improve transcorneal drug permeation and accumulation in anterior ocular tissues following topical administration.

The potential of stereoisomeric prodrugs to circumvent P-gp-mediated cellular efflux was studied. [14C]-Erythromycin was selected as a model substrate of P-gp. Cellular uptake studies were performed in MDCK-MDR1 cells as this cell line is widely employed to study P-gp interactions with substrate drugs $(30,35-37,43)$. As shown in Fig. 3, cellular uptake of [14C]-erythromycin was significantly elevated in the presence of prednisolone. About a 2.3-fold enhancement in uptake was observed indicating that prednisolone is a $\mathrm{P}$-gp substrate. $\mathrm{P}$-gp is known to play a significant role in limiting cellular uptake and transport of prednisolone (6,15-19). Results obtained from this study are consistent with these reports.

Interestingly, [14C]-erythromycin uptake remained unaltered in the presence of DP. This result suggested that DP may not have substrate affinity towards P-gp. This result is consistent with recent reports from our laboratory demonstrating poor recognition of amino acid prodrugs by $\mathrm{P}-\mathrm{gp}(35,36)$. Similarly, no significant rise in the uptake process is observed in the presence of LDP, DLP, and DDP. This result suggests that stereoisomeric prodrugs may not be recognized as substrates by P-gp relative to prednisolone. Significant evasion of $\mathrm{P}$-gp renders these prodrug potential candidates for generating higher corneal absorption and higher anterior tissue levels following topical administration.

In addition to efflux pumps, peptide transporters are highly expressed on the apical surface of corneal epithelial cells (2123). This influx transporter has been widely targeted to improve corneal drug absorption due to its high affinity, capacity, and broad substrate specificity. For investigating substrate affinity towards peptide transporters, cellular uptake of [3H]-Gly-Sar was conducted in the presence and absence of prodrugs in MDCK-MDR1 cells. This cell line was selected as it highly expresses peptide transporters (44). Results obtained from this

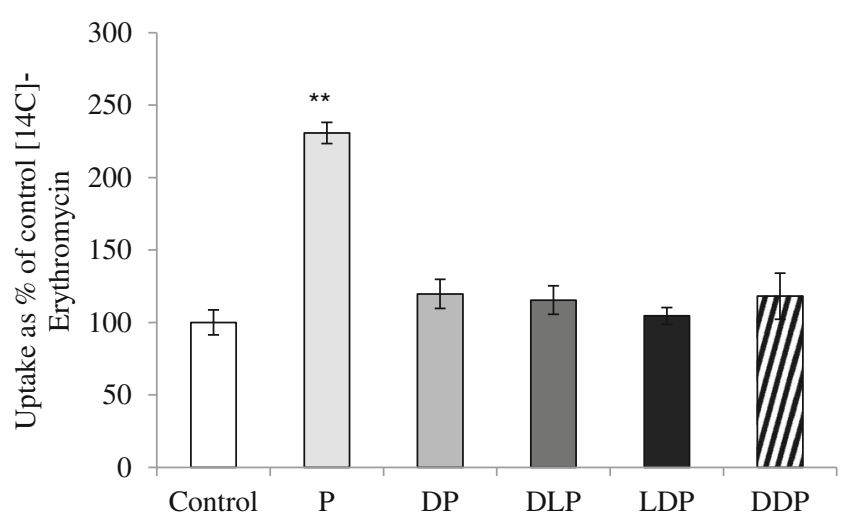

Fig. 3. Cellular uptake of [14C]-erythromycin in MDCK-MDR1 cells in the absence and presence of prednisolone and prodrugs in DPBS $\left(\mathrm{pH} \mathrm{7.4)}\right.$ at $37^{\circ} \mathrm{C}$. Each data point is represented as mean \pm standard deviation $(n=4)$. Uptake is expressed as percentage of control ([14C]erythromycin). Asterisks (**) represent significant difference from the control $(p<0.05)$

study are depicted in Fig. 4. [3H]-Gly-Sar uptake was significantly inhibited in the presence of cold Gly-Sar (2 mM). This inhibition suggested that peptide transporter is functionally active in MDCK-MDR1 cells. The uptake process remained unaltered in the presence of prednisolone $(100 \mu \mathrm{M})$ indicating none or very little affinity towards peptide transporters. Similarly, DP did not generate any significant inhibition in the uptake process. This result indicated that DP may not have high substrate affinity towards peptide transporters.

Interestingly, LDP and DLP prodrugs produced significant inhibition of $[3 \mathrm{H}]$-Gly-Sar uptake. LDP and DLP generated about 55 and $36 \%$ inhibition, respectively. This result suggested that LDP and DLP are recognized by peptide transporters as excellent substrates. However, DDP displayed no significant inhibition of the uptake process. This data indicated that DDP does not possess substrate affinity towards peptide transporters. Previously, LLP prodrug has demonstrated high affinity towards peptide transporters and generated about $60 \%$ inhibition of Gly-Sar uptake (20). Based on these results, it can be concluded that prodrug recognition by peptide transporter is highly dependent on the configuration of amino acids in the peptide structure. For instance, prodrugs with L-isomer amino acid in the terminal (LDP) displayed a significant interaction with peptide transporter. Whereas, prodrug with $\mathrm{D}$-isomer at the terminal (DLP) has generated comparatively lower affinity relative to L-isomer (LDP). However, the presence of two D-isomers in the peptide prodrug structure (DDP) resulted in the loss of affinity towards peptide transporters. Moreover, the presence of two Lisomers in the peptide structure (LLP) displayed maximal affinity towards peptide transporters. Our findings suggest that all those prodrugs containing L-isomers (LLP, DLP, and LDP) may translocate by peptide transporters and simultaneously circumvent efflux by P-gp. On the other hand, DDP prodrug can bypass P-gp-mediated cellular efflux but may not be transported by peptide transporters. Based on these observations, LDP and DLP prodrugs are expected to generate maximal corneal absorption following topical administrations. Moreover, results obtained from this study are consistent with those observed for stereoisomeric prodrugs of saquinavir and acyclovir $(32,33)$. Dipeptide prodrugs of acyclovir and ganciclovir have displayed significant improvements in transcorneal permeability relative 


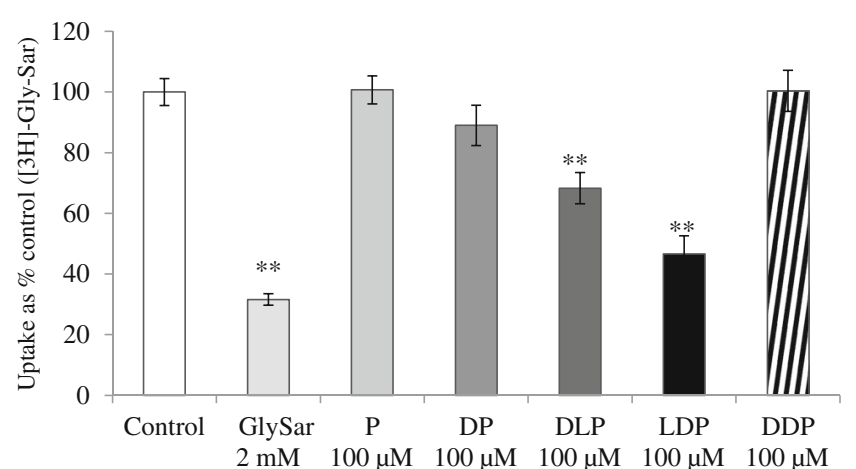

Fig. 4. Cellular uptake of $[3 \mathrm{H}]-$ Gly-Sar in MDCK-MDR1 cells in the absence and presence of prednisolone (P) and prodrugs in DPBS $(\mathrm{pH}$ 7.4) at $37^{\circ} \mathrm{C}$. Each data point is represented as mean \pm standard deviation $(n=4)$. Uptake is expressed as percentage of control ([3H]-Gly-Sar). Asterisks (**) represents significant difference from the control $(p<0.05)$

to unmodified parent drugs $(23,25,26,29,45)$. Half-lives displayed by LLACV, LDACV, and DLACV in intestinal homogenates are $<0.08,1$, and $6 \mathrm{~h}$, respectively. Similarly, longer half-life values of LDACV $(0.49 \mathrm{~h})$ and DLACV $(2.8 \mathrm{~h})$ are observed in liver homogenates relative to LLACV $(<0.008 \mathrm{~h})$. Degradation rates observed for LDACV and DLACV were 11.8- and 15-fold lower compared to LLACV. Similarly, LDACV and DLACV exhibited lower degradation rate constants in cornea, aqueous humor, iris-ciliary body, and lens homogenates relative to LLACV. These results clearly indicate that incorporation of D-isomers significantly reduces enzymatic hydrolysis of dipeptide prodrugs.

\section{Transepithelial Transport Study}

Apical to basolateral (A-B, absorptive direction) transport across MDCK-MDR1 cells was carried out to examine the potential of stereoisomeric prodrugs to overcome P-gpmediated cellular efflux. Previously, we determined transepithelial bidirectional (A-B and $\mathrm{B}-\mathrm{A}$ ) transport of prednisolone across MDCK-MDR1 cells (20). Apparent A$\mathrm{B}$ and $\mathrm{B}-\mathrm{A}$ permeability values generated by prednisolone were $1.3 \pm 0.2 \times 10^{-5}$ and $2.9 \pm 0.5 \times 10^{-5} \mathrm{~cm} / \mathrm{s}$, respectively. Efflux ratio was found to be approximately 2.2 , indicating a significant role of P-gp in modulating prednisolone transport. Results obtained from this study are presented in Fig. 5.

DP and DDP generated approximately 1.3- and 1.4-fold higher permeability in the absorptive direction relative to prednisolone. As observed in cellular uptake studies, DP and DDP were recognized as poor substrates of peptide transporters (Fig. 4). However, these compounds displayed no substrate affinity towards P-gp transporter (Fig. 3), which may have resulted in a slight increase in the A-B transport. On the other hand, LP generated about a 1.7-fold higher A-B transport. This enhancement in the permeability may possibly be due to recognition by peptide transporter and evasion of P-gp-mediated cellular efflux (20). This result supports the assumption that the configuration of amino acids in the prodrug structure might play an important role in transport regulation particularly peptide transporters. Although DDP exhibited superior aqueous solubility and buffer stability, poor substrate affinity towards peptide transporter may be the overall determining factors responsible for poor transport in the absorptive direction.

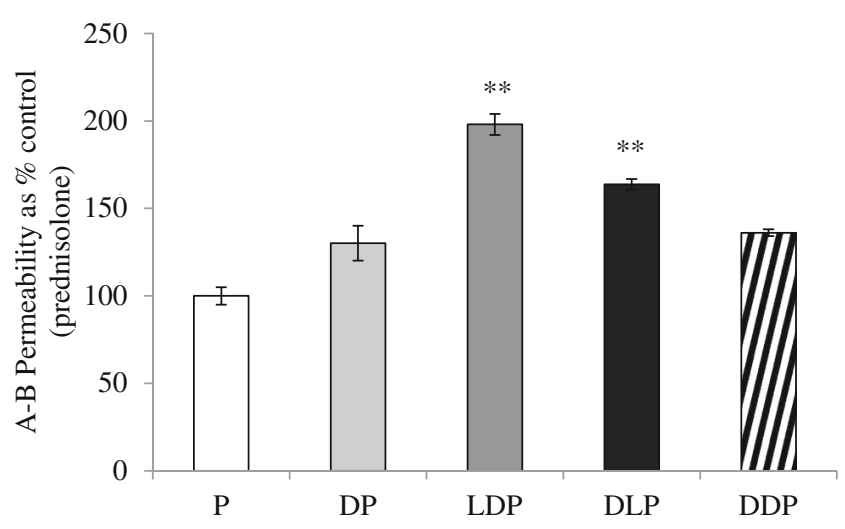

Fig. 5. Cellular permeability studies of prednisolone and its prodrugs. A-B permeability rates of prednisolone and prodrugs across MDCKMDR1 cells. Each point is expressed as mean \pm standard deviation. Asterisks (**) indicate significant difference from control (prednisolone, $p<0.05)$

LDP and DLP prodrugs exhibited significantly higher transport rates in the A-B direction across MDCK-MDR1 cells. Apparent A-B permeability produced by LDP and DLP are 1.98- and 1.63-fold higher relative to prednisolone. This significant enhancement in the transport process was apparent due to both P-gp circumvention and peptide transporter recognition of LDP and DLP. Based on these results, it can be anticipated that LDP and DLP prodrugs might produce higher concentrations in the anterior tissues following topical administration. Previously, LLP displayed about a 2.6-fold higher transport rate in the absorptive direction relative to prednisolone (20). Hence, amino acid configuration (D/L-isomers) in the dipeptide prodrug structure plays a crucial role in determining the transport of prodrugs. Compounds with two L-amino acid isomers (LLP) displayed maximal transport relative to prodrugs containing single L-amino acid isomer (LDP and DLP).

\section{SIRC Cell Homogenate Study}

SIRC cell homogenate study was carried out to determine the effect of D-amino acid isomers on enzymatic degradation of stereoisomeric prodrugs. Results obtained from this

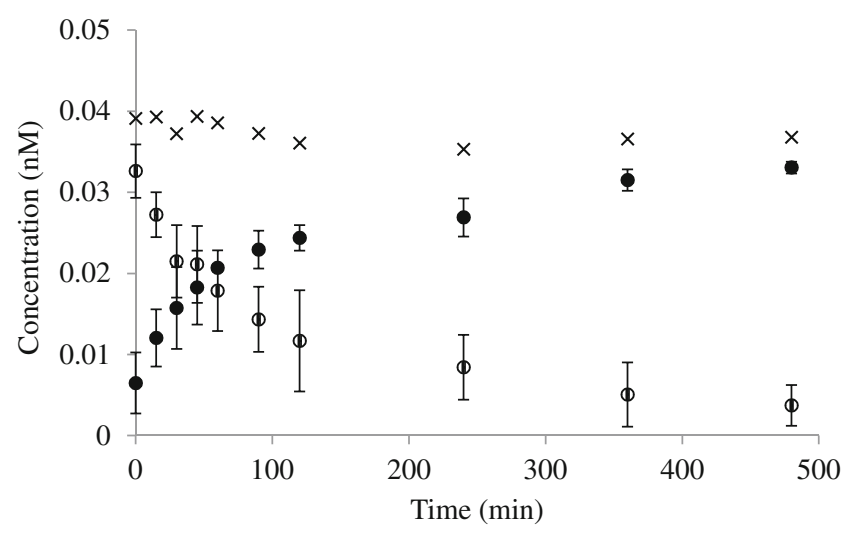

Fig. 6. SIRC cell homogenate study of DP in DPBS (pH 7.4) at $37^{\circ} \mathrm{C}$. White triangle represents regenerated prednisolone from DP (black triangle). Letter $x$ represents total concentration (DP+prednisolone) at each time point 

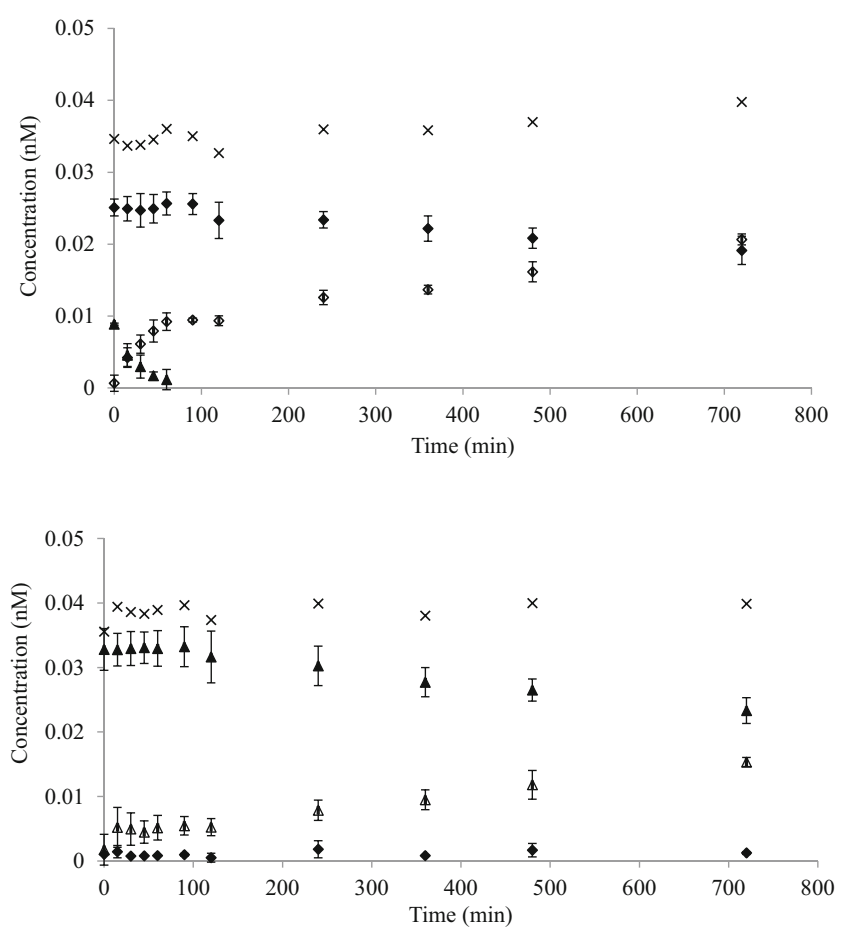

Fig. 7. Degradation profile of DLP (a) and LDP (b) in SIRC cell homogenate in DPBS $\left(\mathrm{pH} \mathrm{7.4)}\right.$ at $37^{\circ} \mathrm{C}$. a White triangle represents regenerated prednisolone from DLP (black triangle) and LDP (). Letter $x$ represents total concentration (DLP+LP+prednisolone) or $(\mathrm{LDP}+\mathrm{DP}+$ prednisolone) at each time point. Each data point is expressed as mean \pm standard deviation $(n=4)$

study are depicted in Fig. 6. DP undergoes rapid degradation to regenerate prednisolone. Degradation rate constant and half-life generated for DP are $0.0040 \pm 0.0003 \mathrm{~min}^{-1}$ and 2.7 $\pm 0.2 \mathrm{~h}$, respectively. Degradation half-life displayed by DP in cell homogenate is significantly lower relative to chemical hydrolysis at $\mathrm{pH} 7.4\left(t_{1 / 2}=4.5 \pm 0.9 \mathrm{~h}\right)$. This result indicates that DP is highly susceptible to degradation by esterase class of enzymes. Previously, we investigated the enzymatic stability of LP in SIRC cell homogenates (20). Degradation half-life of LP is approximately $16 \mathrm{~min}$. Results obtained from this study demonstrates that DP is significantly more stable against enzymatic degradation relative to LP. Degradation half-life of DP (160 min) is tenfold longer compared to LP (16 min). A significant rise in degradation half-life suggests that prodrug developed with D-amino acid isomer may be significantly more stable to enzymatic hydrolysis compared to L-isomers.

Enzymatic stability of LDP and DLP in SIRC cell homogenates was also determined. Degradation profiles of LDP and DLP are demonstrated in Fig. 7. In comparison to amino acid prodrug DP, LDP and DLP slowly but significantly converted to reproduce amino acid prodrug (DP or LP) and prednisolone. Degradation rate constants of LDP and DLP are $0.5 \pm 0.03$ and $0.39 \pm 0.04 \times 10^{-3} / \mathrm{min}$, respectively. Degradation half-lives generated by LDP and DLP are approximately $23 \pm 1$ and $29 \pm 2 \mathrm{~h}$, respectively. Interestingly, DDP is observed to be significantly stable with no apparent degradation throughout the length of cell homogenate study.

DLP prodrug may undergo enzyme-mediated degradation at two positions: (a) ester bond and (b) peptide bond. Degradation of ester bond will result in regeneration of prednisolone, whereas cleavage of amide bond will regenerate LP.
During enzymatic stability studies, a finite amount of LP was observed from DLP (Fig. 7a). This result indicates that DLP is primarily hydrolyzed by peptidase enzymes. This regenerated LP is, however, observed to be very unstable and degraded rapidly to regenerate prednisolone. Degradation rate constant and half-life of regenerated LP from DLP was also determined. Regenerated LP displayed degradation rate constant and half-life of approximately $0.034 \mathrm{~min}^{-1}$ and $20 \mathrm{~min}$, respectively. These values are similar to those obtained during enzymatic hydrolysis of LP and LLP (20). This observation indicates that LP is not only enzymatically unstable but also undergoes degradation following regeneration from LLP and DLP. A large amount of prednisolone was regenerated throughout the length of study, indicating direct regeneration of prednisolone from DLP. This result indicates that DLP significantly undergoes esterase-mediated degradation to produce parent drug. Regeneration of prednisolone is extremely crucial as the parent drug will be freely available to elicit antiinflammatory responses in anterior ocular tissues.

Similarly, LDP degraded enzymatically to reproduce DP and prednisolone. A finite amount of DP and prednisolone was observed at all time points of the study. This result suggested that LDP undergoes enzymatic degradation by both esterase and peptidase class of enzymes. Interestingly, regenerated DP was also observed at all time points indicating significant stability towards enzymatic degradation. Moreover, continuous regeneration of prednisolone was observed, which may be due to enzymatic degradation of LDP and regenerated DP. Results obtained from this study clearly indicate that dipeptide prodrugs produced using L-amino acid isomers are significantly unstable towards enzymatic degradation compared to D-amino acid isomers. Importantly, stereoisomeric prodrugs degrade by both esterase and peptidase class of enzymes.

\section{CONCLUSION}

The present study suggests that stereoisomeric prodrug is a viable strategy to improve the corneal absorption of prednisolone following topical administration. These compounds displayed superior aqueous solubility and bypassed P-gpmediated cellular efflux of prednisolone. Moreover, these compounds are recognized by peptide influx transporters, which are highly expressed on the apical surface of the corneal epithelium. Prodrugs display excellent permeability, and the compounds are hydrolyzed by peptidases and esterases to produce intermediate amino acid prodrug (LP or DP) and prednisolone. Prodrugs produced with D-isomers are significantly more stable to both chemical and enzymatic degradation relative to L-isomers. Based on the results obtained from this study, stereoisomeric prodrugs may be an alternative strategy to deliver prednisolone into anterior ocular tissues following topical administration.

\section{REFERENCES}

1. Hedayatfar A et al. Comparison of efficacy and ocular surface toxicity of topical preservative-free methylprednisolone and preserved prednisolone in the treatment of acute anterior uveitis. Cornea. 2014;33(4):366-72.

2. Lane SS, Holland EJ. Loteprednol etabonate $0.5 \%$ versus prednisolone acetate $1.0 \%$ for the treatment of inflammation after cataract surgery. J Cataract Refract Surg. 2013;39(2):168-73. 
3. Hossain MM et al. Diclofenac sodium and prednisolone acetate ophthalmic solution in controlling inflammation after cataract surgery. Mymensingh Med J. 2010;19(3):343-7.

4. Arellanes-Garcia L et al. Efficacy of prednisolone and rimexolone in HLA-B27 positive patients with acute anterior uveitis. Gac Med Mex. 2005;141(5):363-6.

5. Biswas $\mathrm{J}$ et al. Efficacy and safety of $1 \%$ rimexolone versus $1 \%$ prednisolone acetate in the treatment of anterior uveitis-a randomized triple masked study. Int Ophthalmol. 2004;25(3):147-53.

6. Hariharan S et al. Enhanced corneal absorption of erythromycin by modulating P-glycoprotein and MRP mediated efflux with corticosteroids. Pharm Res. 2009;26(5):1270-82.

7. Verstraelen J, Reichl S. Expression analysis of MDR1, BCRP and MRP3 transporter proteins in different in vitro and ex vivo cornea models for drug absorption studies. Int J Pharm. 2013;441(12):765-75.

8. Dey S et al. Molecular evidence and functional expression of Pglycoprotein (MDR1) in human and rabbit cornea and corneal epithelial cell lines. Invest Ophthalmol Vis Sci. 2003;44(7):2909-18.

9. Verstraelen J, Reichl S. Multidrug resistance-associated protein (MRP1, 2, 4 and 5) expression in human corneal cell culture models and animal corneal tissue. Mol Pharm. 2014;11(7):2160-71.

10. Karla PK et al. Expression of multidrug resistance associated protein 5 (MRP5) on cornea and its role in drug efflux. J Ocul Pharmacol Ther. 2009;25(2):121-32.

11. Karla PK et al. Molecular evidence and functional expression of a novel drug efflux pump (ABCC2) in human corneal epithelium and rabbit cornea and its role in ocular drug efflux. Int J Pharm. 2007;336(1):12-21.

12. Karla PK, Pal D, Mitra AK. Molecular evidence and functional expression of multidrug resistance associated protein (MRP) in rabbit corneal epithelial cells. Exp Eye Res. 2007;84(1):53-60.

13. Hariharan $\mathrm{S}$ et al. Interaction of ocular hypotensive agents (PGF2 alpha analogs-bimatoprost, latanoprost, and travoprost) with MDR efflux pumps on the rabbit cornea. J Ocul Pharmacol Ther. 2009;25(6):487-98.

14. Dey S, Gunda S, Mitra AK. Pharmacokinetics of erythromycin in rabbit corneas after single-dose infusion: role of P-glycoprotein as a barrier to in vivo ocular drug absorption. J Pharmacol Exp Ther. 2004:311(1):246-55.

15. Van der Heyden S et al. Influence of P-glycoprotein modulation on plasma concentrations and pharmacokinetics of orally administered prednisolone in dogs. Am J Vet Res. 2012;73(6):900-7.

16. Troutman MD, Thakker DR. Efflux ratio cannot assess Pglycoprotein-mediated attenuation of absorptive transport: asymmetric effect of P-glycoprotein on absorptive and secretory transport across Caco-2 cell monolayers. Pharm Res. 2003;20(8):1200-9.

17. Karssen AM et al. The role of the efflux transporter Pglycoprotein in brain penetration of prednisolone. J Endocrinol. 2002;175(1):251-60.

18. Oka A et al. Secretory transport of methylprednisolone possibly mediated by P-glycoprotein in Caco-2 cells. Biol Pharm Bull. 2002;25(3):393-6.

19. Nakayama A et al. Different absorption behaviors among steroid hormones due to possible interaction with P-glycoprotein in the rat small intestine. Biol Pharm Bull. 1999;22(5):535-8.

20. Sheng, Y., et al., Prodrug approach to improve absorption of prednisolone. Int J Pharm. 487(1-2): p. 242-9

21. Kadam RS, Vooturi SK, Kompella UB. Immunohistochemical and functional characterization of peptide, organic cation, neutral and basic amino acid, and monocarboxylate drug transporters in human ocular tissues. Drug Metab Dispos. 2013;41(2):466-74.

22. Xiang CD et al. Characterization of human corneal epithelial cell model as a surrogate for corneal permeability assessment: metabolism and transport. Drug Metab Dispos. 2009;37(5):992-8.

23. Anand BS, Mitra AK. Mechanism of corneal permeation of Lvalyl ester of acyclovir: targeting the oligopeptide transporter on the rabbit cornea. Pharm Res. 2002;19(8):1194-202.

24. Jwala $\mathrm{J}$ et al. Ocular sustained release nanoparticles containing stereoisomeric dipeptide prodrugs of acyclovir. J Ocul Pharmacol Ther. 2011;27(2):163-72.
25. Gunda S, Hariharan S, Mitra AK. Corneal absorption and anterior chamber pharmacokinetics of dipeptide monoester prodrugs of ganciclovir (GCV): in vivo comparative evaluation of these prodrugs with Val-GCV and GCV in rabbits. J Ocul Pharmacol Ther. 2006;22(6):465-76.

26. Anand BS et al. In vivo ocular pharmacokinetics of acyclovir dipeptide ester prodrugs by microdialysis in rabbits. Mol Pharm. 2006;3(4):431-40.

27. Katragadda S, Talluri RS, Mitra AK. Modulation of Pglycoprotein-mediated efflux by prodrug derivatization: an approach involving peptide transporter-mediated influx across rabbit cornea. J Ocul Pharmacol Ther. 2006;22(2):110-20.

28. Katragadda S, Talluri RS, Mitra AK. Simultaneous modulation of transport and metabolism of acyclovir prodrugs across rabbit cornea: an approach involving enzyme inhibitors. Int J Pharm. 2006;320(1-2):104-13.

29. Majumdar S et al. Dipeptide monoester ganciclovir prodrugs for treating HSV-1-induced corneal epithelial and stromal keratitis: in vitro and in vivo evaluations. J Ocul Pharmacol Ther. 2005;21(6):463-74.

30. Wang Z, Pal D, Mitra AK. Stereoselective evasion of P-glycoprotein, cytochrome P450 3A, and hydrolases by peptide prodrug modification of saquinavir. J Pharm Sci. 2012;101(9):3199-213.

31. Hutt AJ, O'Grady J. Drug chirality: a consideration of the significance of the stereochemistry of antimicrobial agents. J Antimicrob Chemother. 1996;37(1):7-32.

32. Talluri RS et al. Synthesis, metabolism and cellular permeability of enzymatically stable dipeptide prodrugs of acyclovir. Int $\mathbf{J}$ Pharm. 2008;361(1-2):118-24.

33. Zhiying Wang SL, Sheng Y, Samanta S, Pal D, Mitra AK. Stereoisomeric peptide prodrug modification to improve intestinal absorption of saquinavir: synthesis and in vitro evaluation. Int $\mathbf{J}$ Pharm Eng. 2013;1(2):93-112.

34. Patel $\mathrm{M}$ et al. Molecular and functional characterization of riboflavin specific transport system in rat brain capillary endothelial cells. Brain Res. 2012;1468:1-10.

35. Patel $\mathrm{M}$ et al. Amino acid prodrug of quinidine: an approach to circumvent P-glycoprotein mediated cellular efflux. Int J Pharm. 2014;464(1-2):196-204.

36. Patel $\mathrm{M}$ et al. Amino acid prodrugs: an approach to improve the absorption of HIV-1 protease inhibitor, lopinavir. Pharm (Basel). 2014;7(4):433-52.

37. Luo S et al. Targeting SVCT for enhanced drug absorption: synthesis and in vitro evaluation of a novel vitamin $\mathrm{C}$ conjugated prodrug of saquinavir. Int J Pharm. 2011;414(1-2):77-85.

38. Agarwal $\mathrm{S}$ et al. Peptide prodrugs: improved oral absorption of lopinavir, a HIV protease inhibitor. Int J Pharm. 2008;359(1-2):714.

39. Suresh K et al. Small neutral amino acid ester prodrugs of acyclovir targeting amino acid transporters on the cornea: possible antiviral agents against ocular HSV-1 infections. Ophthalmol Eye Dis. 2010;2:43-56.

40. Jain $\mathrm{R}$ et al. Circumventing P-glycoprotein-mediated cellular efflux of quinidine by prodrug derivatization. Mol Pharm. 2004:1(4):290-9.

41. Kawazu K et al. Characterization of cyclosporin A transport in cultured rabbit corneal epithelial cells: P-glycoprotein transport activity and binding to cyclophilin. Invest Ophthalmol Vis Sci. 1999;40(8):1738-44.

42. Kawazu K et al. Transport of acebutolol through rabbit corneal epithelium. Biol Pharm Bull. 2006;29(4):846-9.

43. Kwatra D et al. Interaction of gatifloxacin with efflux transporters: a possible mechanism for drug resistance. Int J Pharm. 2010;395(1-2):114-21.

44. Agarwal S et al. Functional characterization of peptide transporters in MDCKII-MDR1 cell line as a model for oral absorption studies. Int J Pharm. 2007;332(1-2):147-52.

45. Anand B, Nashed Y, Mitra A. Novel dipeptide prodrugs of acyclovir for ocular herpes infections: bioreversion, antiviral activity and transport across rabbit cornea. Curr Eye Res. 2003;26(34):151-63. 